\title{
UNUSUAL SIMULTANEOUS RUPTURE OF AMOEBIC ABSCESS OF BOTH LIVER LOBES (INTRAPERITONEAL)
}

\author{
H.G. Vyas ${ }^{1}$, Vimal Bhandari², Debasis Naik ${ }^{3}$, Gopalakrishnan $G^{4}$, Anuja Vyas ${ }^{5}$
}

\section{HOW TO CITE THIS ARTICLE:}

H.G. Vyas, Vimal Bhandari, Debasis Naik, Gopalakrishnan G, Anuja Vyas. "Unusual Simultaneous Rupture of Amoebic Abscess of both Liver Lobes (Intraperitoneal)". Journal of Evolution of Medical and Dental Sciences 2014; Vol. 3, Issue 03, January 20; Page: 597-600, DOI:10.14260/jemds/2014/1871

ABSTRACT: Amebic liver abscess (ALA) is the most frequent extraintestinal manifestation of Entamoeba histolytica infection. It is largely a disease of tropical and developing countries and is also a common problem in India. Approximately $80 \%$ of the abscesses are solitary, $83 \%$ of these are located in the right lobe and $17 \%$ are located in the left lobe of the liver. Pleuropulmonary complications of ALA are reported in $20 \%$ of cases and rupture into peritoneal cavity occurs in 6-9\% of patients. Rupture into the peritoneal cavity more often occurs with left-sided abscesses. We present a case of simultaneous rupture of amebic abscess of both liver lobes (intraperitoneal) which as per our knowledge has not yet been reported.

KEYWORDS: Amebic liver Abscess, simultaneous rupture of both liver lobe abscess, amebic peritonitis, intraperitoneal rupture.

INTRODUCTION: Amebiasis is a widespread parasitic disease caused by Entamoeba histolytica. Amebiasis most commonly results in asymptomatic colonisation of gastrointestinal tract, but some patients may develop intestinal invasive disease or extra-intestinal disease - amebic liver abscess being the most common ${ }^{1}$. Approximately $80 \%$ of the abscesses are solitary, $83 \%$ of these are located in the right lobe and $17 \%$ are located in the left lobe of the liver ${ }^{2}$. Rupture into the peritoneum with peritonitis is infrequent; when it does occur it occurs with left-sided abscesses ${ }^{3}$. We present a case of simultaneous rupture of amebic abscess of both liver lobes (intraperitoneal) which as per our knowledge has not yet been reported.

CASE REPORT: A 47 year old alcoholic presented with fever, pain abdomen and distension of abdomen for the last 15 days. Patient was dyspneic and his chest examination revealed bilateral coarse crepitations. On abdominal examination, it was tense, distended, tenderness was present all over the abdomen, guarding was present and bowel sounds were absent. His white blood cell count was $27,200 / \mathrm{mm}^{3}$. Serum Bilirubin and liver enzymes were within normal limit. Serum albumin was $2.1 \mathrm{~g} / \mathrm{dl}$. Blood urea and serum creatinine was normal. Coagulation profile was deranged (INR - 1.7) was corrected after FFP transfusion (INR - 1.34). Chest X-ray (dated 2 days back) revealed elevated right dome of diaphragm (Fig.1) and Ultrasound Abdomen (dated 2 days back) revealed left lobe liver abscess 11.4 x $10.8 \times 7.7 \mathrm{~cm}$ (volume - $506 \mathrm{cc}$ ) with subcapsular collection of 250cc in the left lobe communicating with the liver abscess with thickened walls of caecum and moderate ascites (Fig.2). Patient was taken up for surgery. Exploratory laparotomy revealed 2 liters of seropurulent septated collection with pus flakes in the peritoneal cavity, ruptured right lobe liver abscess $5 \times 6$ $\mathrm{cm})$ occupying segment 7 with ruptured left lobe liver abscess $(11 \mathrm{x} 11 \mathrm{~cm})$ occupying segment 2 and 3 for which lavage of the peritoneal and abscess cavities with drain placement adjacent to both abscess cavities and in pelvis was done. Post-operatively, patient had a few spikes of fever; pus gram 
stain revealed no organism and culture sensitivity revealed no growth. Amebic serology (E. histolytica IgG ELISA) was strongly reactive. The right lobe abscess cavity initially drained around $700 \mathrm{ml}$ of bile, output gradually got reduced and the drain was removed in the $5^{\text {th }}$ postoperative day after its 24 hour output was near to zero for two consecutive days. The left lobe abscess cavity initially drained around $1000 \mathrm{ml}$ of bile which also gradually got decreased. Patient was discharged with the drain adjacent to the left lobe abscess cavity with a 24 hour output of around $400 \mathrm{ml}$ at the end of $3^{\text {rd }}$ week with anti - amebic therapy.

DISCUSSION: Amebiasis is largely a disease of tropical and developing countries but is also a significant problem in developed countries because of immigration and travel between countries ${ }^{3}$. Amebic liver abscess is its most common extraintestinal manifestation ${ }^{1}$. The typical clinical picture of ALA is a patient 20 to 40 years of age who has recently travelled to an endemic area, with fever, chills, anorexia, right upper quadrant pain and tenderness, and hepatomegaly3.

The most common complaint is fever followed by abdominal pain which is most often located in the right upper quadrant. Cough and chest pain are the most frequent pulmonary symptoms and an elevated WBC count is the most consistent laboratory abnormality ${ }^{4}$. The most common LFT abnormality is an elevated PT-INR level ${ }^{3}$.

A number of serological tests have been devised. The indirect hemagglutinin test which was used extensively in the past (sensitivity 90\%) has largely been replaced by Enzyme Immunoassays (EIAs), which are simple, rapid and inexpensive tests (sensitivity $99 \%$ and specificity $>90 \%$ ) $^{3}$.

Plain chest radiographs are abnormal in approximately $50 \%$ of cases, usually demonstrating an elevated right diaphragm, pleural effusion or atelectasis. Ultrasound abdomen might show hypoechoic and heterogeneous rounded lesion abutting the liver capsule without significant rim echoes. CECT Abdomen is more sensitive than Ultrasound and is helpful in differentiating amebic from pyogenic abscess ${ }^{3}$.

Metronidazole $750 \mathrm{mg}$ orally, three times daily for 10 days is the mainstay of treatment of amebic liver abscess ${ }^{3}$. Abscess of less than $5 \mathrm{~cm}$ can be treated with metronidazole alone. However, abscess of more than $10 \mathrm{~cm}$ size must undergo ultrasound guided percutaneous needle aspiration along with metronidazole 5 . Ultrasound guided percutaneous needle aspiration is also recommended in failure to respond to metronidazole therapy in 3 to 5 days, in abscess thought to be at high risk of rupture and abscess larger than $5 \mathrm{~cm}$ in left lobe of liver3.

The most frequent complication of ALA is rupture into the peritoneum, pleural cavity, or pericardium and its incidence ranges from $3 \%$ to $17 \%{ }^{3}$. Amebic peritonitis following intraperitoneal rupture is a serious complication ${ }^{6}$. Although the superior surface of the right lobe of the liver is the commonest site of involvement, abscess that rupture into the peritoneal cavity usually involve the inferior surface of the liver. It usually presents as abdominal pain, peritonitis and a mass or generalized distension. Laparotomy was advocated in the past for this complication, but now many patients are treated successfully with percutaneous drainage. Laparotomy is advocated in cases of doubtful diagnosis, hollow viscous perforation, fistula formation resulting in hemorrhage or sepsis, and failure of conservative therapy ${ }^{3}$

CONCLUSION: In conclusion, intraperitoneal rupture of ALA though infrequent is a serious complication. It has been associated with significant mortality. Simultaneous rupture of abscess in 
both the liver lobes is a possibility and awareness of such a possibility is likely to result in optimal management. However, if a diagnosis is made in early and anti-amebic treatment started, nonoperative management can produce effective and gratifying results.

\section{FIGURES:}

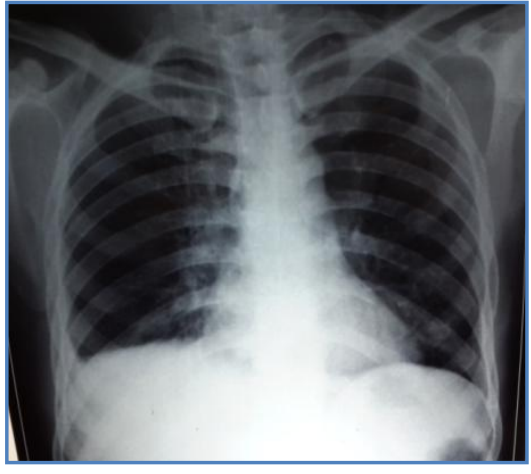

Fig. 1: Chest X-ray dated 2 days before surgery showing elevated right dome of diagphragm.

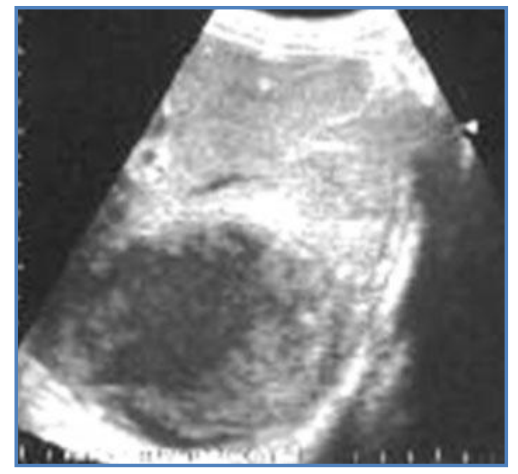

Fig. 2: USG Abdomen showing left lobe liver abscess with subcapsular rupture.

\section{REFERENCES:}

1. Hughes M A, Petri W A Jr. Amebic liver abscess. Infect Dis Clin North Am. Sep 2000; 14(3): 565 - 82, viii.

2. Hibberd P L, Rubin R H. liver abscess - pyogenic and amebic. Oxford textbook of Surgery, $1^{\text {st }}$ edn. Eds. Morris P J, Malt R A. Oxford, Oxford. University Press 1994; pp 1179 - 1186.

3. Sabiston Textbook of Surgery: The Biological basis of Modern Surgical Practice. M. Townsend, JR., R. Daniel Beauchamp, B. Mark Evers and Kenneth L. Mattox.19th ed. The Liver. EIH Limited - Unit Printing Press; 2013. pp: 1445 - 47.

4. Hoffner R J, Kalighbian T, Esekogwes VI, et al. Common presentation of Amebic Liver Abscess. Ann Emerg Med. Sep 1999; 34(3): 351-5.

5. Bammigatti C, Ramasubramanian N, Kadhiravan T, Das A K. Percutaneous needle aspiration in uncomplicated liver abscess: a randomised trial. Trop Doct. Jan 2013; 43(1): 19 - 22.

6. Eggleston F C, Handa A K, Verghese M. Amebic peritonitis secondary to amebic liver abscess. Surgery 1982; 91: $46-8$.

7. DeBakey M E, Oschner A. Hepatic Amebiasis: a 20 years' experience and analysis of 263 cases. Surg Gynecol Obstet (Int Abstr Surg) 1951; 92: 209 - 31. 


\section{AUTHORS:}

1. H.G. Vyas

2. Vimal Bhandari

3. Debasis Naik

4. Gopalakrishnan G.

5. Anuja Vyas

\section{PARTICULARS OF CONTRIBUTORS:}

1. Professor and Head, Department of Surgery, SGT Medical College, Budhera, Gurgaon \& Ex. Associate Professor, Department of General Surgery, V.M.M.C. and Safdarjung Hospital, New Delhi.

2. Associate Professor, Department of General Surgery, V.M.M.C. and Safdarjung Hospital, New Delhi.

3. Post Graduate, Department of General Surgery, V.M.M.C. and Safdarjung Hospital, New Delhi.
4. Post Graduate, Department of General Surgery, V.M.M.C. and Safdarjung Hospital, New Delhi.

5. Post Graduate, Department of Endodentistry, SGT Dental College, Budhera, Gurgaon.

\section{NAME ADDRESS EMAIL ID OF THE CORRESPONDING AUTHOR:}

Dr. H.G. Vyas,

B-304, SGT Campus,

Budhera, Gurgaon.

Email-premharidpac@yahoo.co.in

Date of Submission: 23/12/2013.

Date of Peer Review: 24/12/2013.

Date of Acceptance: 03/01/2014.

Date of Publishing: 14/01/2014 